\title{
Iglesia y cuestión social: \\ la intervención de la Iglesia Católica \\ en la construcción de demandas de educación, tierra y vivienda en el Gran Buenos Aires
}

\author{
Laura Santillán \& Marcela Woods ${ }^{1}$
}

Docentes e investigadoras doctorandas en el Instituto de Cs. Antropológicas
de la Facultad de Filosofia y Letras - UBA

RESUMEN: En este trabajo nuestro objetivo es analizar las modalidades de intervención de agencias de la Iglesia Católica en la construcción territorializada de demandas sectoriales de sectores populares del conurbano bonaerense, mostrando su relación con la transformación de las políticas sociales del Estado hacia el asistencialismo y la terciarización durante las últimas décadas. Para ello presentaremos comparativamente dos casos de estudio, encarados desde un enfoque etnográfico: la construcción de demandas educativas y su progresiva integración en estructuras referenciadas en el marco del Obispado de San Isidro; y la intervención de la Vicaría de Pastoral Social del Obispado de Quilmes en los conflictos sociales entre organizaciones de tierra y vivienda y el estado local. De esta manera nuestro propósito es visibilizar los límites y posibilidades que suponen estas formas de intervención de la Iglesia Católica sobre la recomposición de formas organizativas del campo popular, marcando tanto las especificidades locales e históricas de cada diócesis como la lógica común que las atraviesa y orienta.

PALABRAS CLAVE: Iglesia, Estado, cuestión social, educación, tierra y vivienda. 


\section{Introducción}

La constatación de que la Iglesia Católica se presentaba en las última décadas como un actor cada vez mas relevante para la problematización de la cuestión social nos llevó a indagar su trayectoria y actuaciones en nuestros respectivos casos de estudio. A partir de esta coincidencia de intereses y de integrar el mismo equipo de investigación, ${ }^{2}$ nos planteamos la posibilidad de analizar en forma comparativa la intervención de la Iglesia en las políticas y reivindicaciones sociales, cuestión que nos permite fortalecer y ampliar las conclusiones provisionales a la que habíamos llegado previamente.

En este artículo nuestro objetivo es presentar los avances de este estudio comparativo de las modalidades de intervención de agencias de la Iglesia Católica en la construcción territorializada de demandas sectoriales de sectores populares del conurbano bonaerense, intentando mostrar además la relación entre estas formas de intervención de la Iglesia en la cuestión social con la transformación de las políticas sociales del estado desplegadas en las últimas décadas.

La configuración actual de un nuevo escenario social para el procesamiento de las demandas y la formación de sujetos es producto de los cambios en la relación capital-trabajo que tienen lugar durante la década del 70. En la Argentina un punto de inflexión en este proceso es el programa impuesto por la dictadura militar de 1976 orientado hacia la apertura económica y la desindustrialización y apoyado en mecanismos de clausura sindical y política (Villareal, 1985). La ruptura de identidades colectivas previas y de la capacidad de representación de las instituciones tradicionales de mediación, producto de tales procesos, se profundiza durante la década de los '90 con las medidas neoliberales de Reforma Estructural del Estado impulsadas por el gobierno de Menem 
(1989-1999), sustentadas en el llamado Consenso de Washington (Grassi, Hintze y Neufeld, 1996).

Los rasgos mas sobresalientes para comprender nuestra problematización de estos cambios en el modelo de Estado se resumen en los procesos de descentralización administrativa, la orientación asistencialista y focalizada dada a las políticas sociales y la terciarización de funciones sociales, medidas con las que se pretende paliar las consecuencias del crecimiento exponencial del empobrecimiento y el desempleo que conlleva este nuevo régimen de regulación. ${ }^{3}$ Ello se conforma como una política activa desde el Estado mismo, dirigida a constituirlo en Estado subsidiario, trastocando la noción de derechos sociales por la de "ayuda", puesto que se "desestatalizan" las intervenciones sociales, que pierden así su carácter universalista (Grassi, 1997).

Esta redefinición de la intervención del Estado no supone su "retirada", como postulan algunos autores, sino mas bien una creciente penetración en la vida cotidiana (Holloway, 1994). En tal sentido, Trouillot (2001) plantea el desarrollo de "efectos de Estado", en términos de los procesos y relaciones que tienden enmascarar las divisiones de clase y fragmentar las luchas sociales, y que pueden ser desplegados aún por fuera de sus límites administrativos formales. ${ }^{4}$ Entendiendo entonces por Estado algo mas que el aparato de gobierno, Trouillot propone seguir la pista de estos "efectos" en el terreno, puesto que estarían siendo re-desplegados en sitios inesperados, y lo que es más interesante del planteo, las prácticas y funciones característicos del Estado pueden desarrollarse también desde espacios infra o supra-nacionales tales como ONGs, organismos transestatales como el Banco Mundial etc. produciendo el mismo tipo de "efectos" tendientes a la atomización de los conflictos y luchas sociales.

Esta aproximación nos conduce a discutir las miradas que naturalizan la separación Estado/sociedad civil obliterando su reconocimiento 
como construcción histórica y su mutua interpenetración en la formación de sujetos y "problemas" sociales.

En esta perspectiva resulta significativo indagar el lugar de la Iglesia Católica en relación con el movimiento de privatización y terciarización de las funciones del Estado en el plano de la implementación de las políticas sociales, movimiento concomitante con la tendencia a la territorialización tanto en la formulación de las demandas, orientadas privilegiadamente hacia la reproducción de la vida cotidiana, como en su gestión en el nivel local de gobierno. ${ }^{5}$

Para comprender la orientación hacia la cuestión social de la Iglesia debemos tener en cuenta las fuertes transformaciones experimentadas por la institución desde los años '60 (propiciadas por el Concilio Vaticano II), los conflictos internos y la deslegitimación sufrida, producto de la actuación cómplice de la cúpula eclesial durante la última dictadura militar (1976-1983). Como intento de resolución de esta crisis se irá desarrollando entonces a partir de los años '70 un lento camino de recomposición de la unidad de la institución, que se realizaría prioritariamente en el terreno doctrinario promoviendo una corriente moderada que conduciría hacia la "reconciliación", diluyendo la radicalización de sectores de base del clero nacional, pero también conteniendo al ala mas conservadora. Se pretendía con este centramiento recuperar el arraigo social de la Iglesia y por ese camino reposicionarse como factor de poder en la escena nacional (Di Stéfano y Zanatta, 2000).

Por otra parte la penetración de la Iglesia en la problematización de la cuestión social a nivel territorial coincide temporalmente y a la vez es fortalecida por los cambios en las modalidades de intervención del Estado, expresados en la orientación asistencialista de las políticas sociales y su terciarización hacia entidades de la sociedad civil. En este último proceso, la Iglesia se constituye durante la década del '90 como un interlocutor clave, dado su alto nivel de credibilidad (postulado por el 
Revista de Antropologia, São Paulo, USP, 2005, v. 48 No 1.

Estado), pasando a ser contraparte o gestora de múltiples programas sociales $^{6}$ (Grassi, 2003).

Estos procesos coincidentes de transformaciones en la Iglesia y en el Estado se expresan a la vez como una reorganización del campo de la sociedad civil, acompañada por la reemergencia de discursos acerca de la separación de Estado y sociedad civil y la preeminencia dada al denominado Tercer Sector, desde una apropiación neoliberal de estas nociones. ${ }^{7}$

Esta concepción de la distinción entre Estado y sociedad civil remite a la separación entre lo político y lo económico como condición de la forma de explotación capitalista, que hace ver a las relaciones de producción como un asunto privado entre particulares, oscureciendo la función del Estado como garante de este proceso. ${ }^{8}$

En función de nuestro interés por las formas de intervención de la Iglesia, seguimos a Meiksins Wood (2000), quien alerta sobre los riesgos de los nuevos usos de "sociedad civil" que tienen como común denominador destacar sus funciones positivas. Si bien por un lado, para esta autora, estas nociones apuntan fortalecer las instituciones y relaciones no estatales frente al poder y la opresión del Estado, por otro lado, al identificar a la sociedad civil como una esfera de libertad, al menos potencial, tienden a limitar nuestras resistencias a las coerciones del capitalismo. Esto porque la dominación de clase no se encuentra concentrada en el Estado, como ya había señalado Gramsci al identificar sus raíces culturales e ideológicas en la vida cotidiana, sino que también reside en los distintos espacios de la sociedad civil. Así, la oposición entre coerción, identificada con el Estado, y libertad o acción voluntaria propias de la sociedad civil, invisibiliza la lógica totalizadora del capitalismo. Por su parte Sousa Santos (1998) piensa este problema mas específicamente en relación a los países periféricos y semiperiféricos, y señala que la "reemergencia de la sociedad civil" en los discursos dominantes 
debe relacionarse con un reajuste estructural de las funciones del Estado y la consecuente necesidad de legitimar la transferencia al sector privado no lucrativo de las responsabilidades y servicios sociales no rentables que éste Estado prestaba.

Se hace evidente entonces, una vez aceptado que el poder político no reside únicamente en el Estado y que las instituciones no estatales pueden contribuir a reproducir sus "efectos", la necesidad de comprender y ubicar las intervenciones de la Iglesia dentro este movimiento de "reemergencia de la sociedad civil".

\section{Ubicación de los casos de estudio en el Conurbano Bonaerense}

Nuestra intención es profundizar, tomando como referencia nuestros registros de campo, en las modalidades de intervención de la Iglesia en vinculación a demandas específicas de educación, tierra y vivienda en dos zonas distintas del conurbano bonaerense (compuesto por $25 \mathrm{mu}-$ nicipios que rodean la Capital Federal), que se enmarcan en los obispados de Quilmes y San Isidro. ${ }^{9}$ La relevancia de la comparación entre zona Sur y Norte del conurbano se desprende de las diferencias que exhiben en los procesos de urbanización, los indicadores socio-económicos y las trayectorias asociativas, que ponderamos como factores que contribuyen a explicar la especificidad de las formas que adquiere la intervención estatal y eclesial, en relación con la construcción de demandas desde los sectores populares.

Una tendencia que marcó la configuración urbana del área metropolitana de Buenos Aires ha sido la concentración en la Capital Federal de los sectores de mayor poder adquisitivo y el desplazamiento de los sectores populares hacia las zonas periféricas, sin una correspondencia sa- 
tisfactoria en la cobertura de infraestructura urbana como política estatal (Oszlak, 1986).

Así, el crecimiento de los partidos que rodean la Capital se incrementa con fuerza entre los años ‘ 40 y ‘ 60 , bajo el impulso de la política de sustitución de importaciones que radicó industrias en la periferia y atrajo migrantes internos que se afincaron fundamentalmente en el denominado primer anillo. La expansión hacia el área suburbana de la población de menores recursos se produjo principalmente por medio de loteos populares y la formación de villas.

A partir de fines de los años 60, se abre un período de desnacionalización de la industria y cierre de establecimientos que modifica el patrón territorial, desplazando la urbanización hacia los municipios del segundo anillo, donde vivir es menos costoso aunque se cuenta con menor cobertura de servicios. El ritmo de crecimiento demográfico de los municipios del primer anillo comenzó a disminuir, mientras los del segundo anillo incrementan su ritmo notablemente llegando en los '70 a triplicarse la población que tenían en los '60. Un dato significativo al respecto son las políticas de erradicación de villas de la Capital Federal durante el período dictatorial (Pírez, 1994).

Podemos señalar que desde fines de los ' 60 el crecimiento poblacional se da en condiciones menos favorables ya que los cambios en el modelo de Estado llevan a un abandono de la regulación del proceso de urbanización y de la provisión de servicios e infraestructura por parte del Estado, lo cual afecta sobre todo a la expansión sobre el segundo anillo. Esta responsabilidad debe ser asumida entonces por los propios pobladores a través de la organización colectiva que plantea sus demanda al Estado y contribuye en la ejecución de las obras. Este proceso dio como resultado una urbanización popular espontánea (no guiada por una política demográfica) y de tejido discontinuo y desordenado. 
El municipio de Quilmes se ubica en la zona Sur del Gran Buenos Aires, tiene una población de 575.643 habitantes, siendo el tercero más poblado del conurbano. El porcentaje de población con necesidades básicas insatisfechas (NBI) del distrito es de 21,2 \% (107.859 individuos), algo superior al $19,5 \%$ promedio que muestra el total del conurbano bonaerense. ${ }^{10}$

Si bien este municipio se ubica en el segundo anillo del conurbano, tiene características particulares que lo acercan al modelo urbano del primer anillo, tales como una ocupación poblacional mas antigua, con un consecuente crecimiento demográfico relativamente bajo en términos comparativos, y una densidad de población alta. Sin embargo al mismo tiempo desde los años ' 80 la historia de los sectores populares de Quilmes está atravesada por la experiencia de las tomas de tierras y formación de asentamientos. ${ }^{11}$ Estas experiencias se enmarcan en un proceso de pauperización y deterioro de las condiciones de vida de los sectores populares, y en la transformación de modalidades de organización y lucha. Éstas, al tiempo que se alejan de los espacios fabriles, se trasladan progresivamente hacia el territorio y tienden a distanciarse de las instituciones tradicionales de mediación/representación política. Así, las organizaciones de lucha por la tierra y la vivienda constituyen el sector mas movilizado y con niveles de articulación crecientes entre las organizaciones de base en este distrito y en el Gran Buenos Aires en general.

Los partidos comprendidos en el Obispado de San Isidro, en la zona norte del conurbano, sobresalen por la marcada polarización que exhiben en términos de las condiciones socioeconómicas de su población. Mientras los distritos de San Isidro y Vicente Lopez presentan índices relativamente bajos de pobreza (siguiendo los rasgos generales que marcan los procesos de suburbanización en esta zona, de mayor concentración de sectores con alto poder adquisitivo), los distritos de San Fernando y Tigre incluyen importantes enclaves de pobreza. Estos partidos 
ubicados en el segundo cordón tienen las características sociodemográficas de los partidos más pobres del conurbano con un índice del $23 \%$ de la población total con necesidades básicas insatisfechas. Actualmente, el desarrollo "perimetropolitano" de estos distritos, que tuvo lugar durante la década del 60 a partir de la localización de industrias de peso relativo sobre las rutas de salida de la Capital, se transmutó significativamente en dos tendencias fuertemente contrastantes: la progresiva localización de sectores populares a través de villas y asentamientos en zonas poco favorables para el hábitat y el impacto de las llamadas "nuevas urbanizaciones". Nos referimos a la construcción de barrios privados y "countries" altamente concentrada en esta zona durante los procesos de cambio de los '90 e íntimamente ligados a la privatización de la vida social y redefinición de la regulación del Estado.

Teniendo en cuenta estas especificidades socioterritoriales, nuestro propósito es visibilizar las modalidades de intervención de la Iglesia Católica, los límites y posibilidades que suponen sobre la recomposición de formas organizativas del campo popular, marcando tanto las particularidades locales e históricas de cada diócesis, como la lógica que común que las atraviesa y orienta.

\section{La diócesis de Quilmes. De la defensa de los DDHH a la intervención en la cuestión social}

En este apartado analizaremos las formas de intervención de la Iglesia en relación a las demandas de organizaciones de base orientadas a la problemática de la tierra y la Vivienda en Quilmes. En función de ello tomaremos como eje el proceso de luchas sociales que llevó a la conformación del denominado Consejo Comunitario de Políticas de Tierra y 
Vivienda de Quilmes y las actuaciones del Obispado de Quilmes, y particularmente la vicaría de Pastoral Social, en tal proceso.

Este Consejo es un órgano de gestión participativa y control de recursos para la planificación urbana, creado a fines de 1998, y que aunque con dificultades, se encuentra en actividad. La Comisión Directiva del mismo está compuesta por representantes provenientes del gobierno provincial, municipal, del Honorable Consejo Deliberante de Quilmes (legislativo municipal), del Obispado de Quilmes, de la Universidad de Quilmes, de ONGs del distrito y de las organizaciones comunitarias de tierra y vivienda del distrito; sus objetivos generales son generar una política activa de tierra y vivienda para los sectores populares y hasta el momento ha sido prioritaria en sus actividades la problemática de la regularización dominial. ${ }^{12} \mathrm{El}$ análisis de su creación y dinámica de funcionamiento nos mostró la relevancia de la intervención del Obispado de Quilmes en lo social, y específicamente en conflictos entre organizaciones comunitarias y el Estado local.

Partiremos entonces de la constitución de este Obispado, su perfil particular dentro del Episcopado argentino, y la progresiva intervención en la cuestión social a partir de la relación con las organizaciones de base de tierra y vivienda en el distrito, con el fin de comprender la orientación hacia la mediación y la cooptación que tomaron sus intervenciones.

El Obispado de Quilmes se creó en junio de 1976 y comprende los partidos de Quilmes, Berazategui y Florencio Varela, (todos ubicados en el segundo anillo). El primer Obispo de la diócesis, consagrado en 1976 fue Jorge Novak, hasta su fallecimiento en julio de $2001 .{ }^{13}$ En mayo de 2002 fue consagrado el actual Obispo Luís T. Stökler.

A pesar de lo relativamente reciente de su creación, que coincide con el inicio de la última dictadura militar en el país, ésta ha sido una de las diócesis de actuación mas conocida públicamente en la defensa de los derechos humanos, especialmente en lo referente a la atención de las 
familias de los "desaparecidos", recibiendo denuncias en la comisión diocesana de Justicia y Paz (creada por el mismo Novak con tal fin), e intercediendo por ellos ante autoridades de distintos ámbitos y niveles, llegando con tal fin hasta el Vaticano. De esta manera se diferencia, junto a otros pocos obispos más o menos críticos y comprometidos con las líneas mas progresistas de la Iglesia, de la actuación cómplice de la Conferencia Episcopal Argentina (CEA) hacia la dictadura, siendo ello una expresión más del profundo conflicto que atravesaba la Iglesia Católica Argentina, intensificado desde los años $60 .^{14}$

Así, es posible caracterizar esta etapa fundacional de la diócesis por su defensa de los Derechos Humanos en un marco nacional represivo, con Novak ${ }^{15}$ como protagonista principal, acompañado por un grupo de curas y laicos comprometidos en esta misma línea.

Sin abandonar esta orientación por parte de la cúpula del Obispado, se empieza a destacar hacia el final de la dictadura, ya en franco debilitamiento, la actuación de curas y agentes laicos en el campo social, con un fuerte protagonismo de las Comunidades Eclesiales de Base (de ahora en adelante $\mathrm{CEB}$ ), que se van multiplicando en la diócesis a partir de octubre de 1976. Se estima que hacia 1980, existían en Quilmes alrededor de 60 comunidades compuestas por grupos de 20 a 30 personas. Sumado a la fuerte tradición sindical local (seccional Quilmes-VarelaBerazategui de distintos sindicatos) que estas experiencias recuperan, las CEB constituyeron un factor determinante en el surgimiento de los procesos organizativos de tomas colectivas de tierras y formación de asentamientos, cuyas primeras experiencias se dan justamente en este municipio, en la localidad de San Francisco Solano durante la primavera de 1981 (Zibechi, 2003; Izaguirre y Aristizábal, 1988).

Varios trabajos señalan la relevancia para estas primeras experiencias quilmeñas del papel de las CEB, considerando el apoyo material, su actividad de capacitación popular y, especialmente, la legitimación de 
prácticas que otorga la Iglesia moldeando nuevas ideas sobre la política, la justicia, los derechos etc. (mediante una interpretación cristiana) ante el propio colectivo y hacia el poder político, y sobre todo facilitando un espacio capaz de incorporar las prácticas de los militantes de base. De allí también su importancia como modelo organizativo para la siguiente oleada de tomas y asentamientos que se dieron en todo el conurbano bonaerense (destacando el municipio de La Matanza, donde también fue decisivo el apoyo de las CEB) (Merklen, 1991; Cravino, 1998; Manzano, 2003).

Sin embargo, aunque acordamos con estas aseveraciones, notamos que no se ha profundizado sobre las evidencias señaladas de conflictos internos en las Iglesias diocesanas acerca de la actuación y orientación ideológica de las CEB. Es que en general los estudios que se centran en el análisis de la relación entre iniciativas organizativas populares y presencia de la Iglesia prefieren o tienden a destacar el apoyo positivo, de elemento aglutinador que permite pasar de la acción individual a la colectiva, de identidad, de red de asistencia y de legitimación de prácticas, que implica para estos sujetos la intervención de alguna agencia eclesial en relación a sus proyectos o demandas, pero no los condicionamientos que ello acarrea (Rivarola, 1986; Forni, 1989; Forni y Cárdenas, 2002; entre otros). ${ }^{16}$

En ese sentido, en Quilmes el Obispo crea finalmente en 1983 la Vicaría de Pastoral Social con el objeto de direccionar este movimiento eclesial de base ligado a la conflictividad social territorial. ${ }^{17}$ No obstante, ello no logró evitar conflictos con la cúpula diocesana en relación a la actuación de las CEB, y provocó inclusive desplazamientos de curas comprometidos en esta línea de acción en el intento de moderar la orientación de las comunidades más dinámicas.

Luego de la etapa centrada en la defensa de los DDHH y de la experiencia de las $\mathrm{CEB}$ durante los '80 con su conflictiva relación con la 
cúpula eclesial y ligada a las luchas por la tierra en el distrito (que llevaron a la creación en 1989 de una organización de segundo grado, el Consejo de Asentamientos de Quilmes), comienza a desarrollarse en la diócesis un fuerte interés por la cuestión social que parte ahora de la cúpula misma del Obispado. Este movimiento está en sintonía con la orientación general hegemónica en el Episcopado argentino, orientación que se va fortaleciendo conforme avanzaba el proyecto neoliberal de la mano del gobierno de Carlos Memen durante la década del '90, y se profundizaba la crisis de representación y el crecimiento de la pobreza.

Se trata a nuestro entender de un nuevo ciclo de vinculación activa y planificada del Obispado de Quilmes con organizaciones sociales del distrito, especialmente con las ligadas a las problemáticas de tierra y vivienda, que eran las que había expresado mayor conflictividad en el distrito en los últimos años.

Consideramos como un hecho significativo que puede marcar el inicio de esta nueva etapa, la toma de tierras y Asentamiento de La Sarita, en Quilmes.

Esta toma comienza en octubre de 1995, y desata un importante conflicto donde intervinieron funcionarios municipales, provinciales y nacionales. Una primera repercusión fue la re-activación en su apoyo de la red de organizaciones del Consejo de Asentamientos de Quilmes. Pero los altos niveles de represión en el conflicto tuvieron otras consecuencias significativas: (1) la necesidad de contar con el máximo posible de apoyo externo para "sostener" la toma, lo que llevó también a promover una gran difusión pública en los medios, y (2) la detención por parte de la policía provincial del abogado que defendía a los ocupantes y de tres curas que apoyaban el proceso reivindicativo de la toma. Ambos puntos fueron decisivos para involucrar al propio obispo Novak, que decide "mediar" en el conflicto negociando con el municipio y la provincia y llegando a una resolución favorable a los asentados. 
Es en este punto que el Obispado comienza a desplegar una estrategia activa hacia este conjunto de organizaciones comunitarias y sus referentes: En primer lugar, concretando rápidamente la re-apertura de la Vicaría de Pastoral Social (luego de su efímera etapa 83-86). Y avanzando en esta línea, en el marco de una asamblea del Consejo de Asentamientos donde se evaluaba la resolución de la toma y la eficacia de la negociación del Obispado, el grupo de curas que apoyó la toma realiza una propuesta de incorporación de dos dirigentes del Consejo de Asentamientos a la Vicaría de Pastoral Social, conformando dentro de ella una Comisión de Tierra y Vivienda. La propuesta fue aceptada y dos dirigentes comenzaron a trabar relaciones en ese ámbito, ubicándose así en el lugar estructural del mediador entre las autoridades religiosas y las demandas de las organizaciones comunitarias. ${ }^{18}$

En septiembre de 1996 un nuevo conflicto contribuye a afianzar estas relaciones promovidas por la Iglesia: se trata de un proyecto del ejecutivo municipal de imposición de una Tasa de Fomento a las situaciones de irregularidad en la tenencia de la tierra (afectando a villas y Asentamientos), con el objetivo declarado de hacer obras en el futuro, a través de un Fondo de Tierras también proyectado, aunque sin garantías suficientes ni participación de la comunidad, de acuerdo a la evaluación de las organizaciones del Consejo de Asentamientos, que coordinó la oposición al proyecto. En esta oportunidad es el municipio el que solicita la mediación del Obispado, que delega esta tarea en la Vicaría de Pastoral Social, evitándose la concreción del proyecto oficial.

De allí en adelante la Vicaría juega un papel convocante y articulador de un conjunto de organizaciones comunitarias de base y ONGs, que exceden al Consejo de Asentamientos, interesadas en la problemática del hábitat popular.

Es en este marco (en reuniones en la Vicaría de Pastoral Social) donde se empieza a desarrollar el proyecto de ordenanza del Consejo Co- 
munitario de Políticas de Tierra y Vivienda (como contraproyecto del Fondo de Tierra propuesto por el municipio), que se presenta a principios de 1998 al Consejo Deliberante de Quilmes. El apoyo del Obispado fue crítico para su posterior aprobación en noviembre de ese año, integrando además la Comisión Directiva de este órgano colectivo de gestión.

El mayor interés de este proceso reside en el salto cualitativo en la capacidad de articulación de las organizaciones populares, a partir de la creciente integración de demandas y de nuevas organizaciones en el Consejo Comunitario, la definición de prioridades y acciones consensuadas colectivamente y la movilización de los vecinos frente al Estado para el logro de las demandas planteadas, disputando el control de los recursos para el sector. ${ }^{19}$

No obstante, esta lucha por recursos en el seno del propio Estado debe ser entendida tanto como un nuevo espacio para la formulación de demandas, como también en el sentido de una respuesta del estado en términos de procesamiento de conflictos por vía de la adecuación a las formas y tiempos de la burocracia estatal y (tal vez mas importante) de la separación de las luchas por la tierra y la vivienda de otras demandas y luchas surgidas de los modos de vida de los sectores populares empobrecidos (salud, educación, alimentación etc.)

Podemos decir entonces que la concreción y funcionamiento de este Consejo Comunitario tuvo como condición de posibilidad el apoyo del Obispado y la tradición organizativa de las tomas y asentamientos (con la creación del Consejo de Asentamientos de Quilmes). A la vez, constituye un punto de inflexión en la relación Iglesia - organizaciones comunitarias - Estado local, al modificar el campo de fuerzas local unificando actores del campo popular.

Por otro lado, no obstante la Iglesia (en particular el espacio de la Vicaría de Pastoral Social) ${ }^{20}$ parece haberse fortalecido durante este 
mismo proceso como instancia de mediación necesaria siempre presente para sostener el proceso. Así, en los momentos críticos de enfrentamiento con el poder, las organizaciones nucleadas en el Consejo Comunitario recurren por igual a la presión de la movilización popular y al apoyo del Obispado a través de la Vicaría.

Cuáles son los límites del apoyo de la Iglesia hacia formas de organización "autónomas" (o de oposición al Estado)? Debemos tener en cuenta para ello que las organizaciones articuladas en el Consejo Comunitario de Políticas de Tierra y Vivienda, que buscaron el apoyo del Obispado, son organizaciones sociales de base que plantean al Estado demandas sectoriales. Pertenecen al campo definido como "sociedad civil" donde la Iglesia se inserta disputando la orientación de las prácticas de estas organizaciones en el sentido de instituir valores comunitarios. Como tendencia general, estos valores comunitarios promovidos por la institución tienden a diferenciarlas de las organizaciones políticas, identificando como parte de un sustrato cultural común de "religiosidad popular" prácticas de estas organizaciones sociales de base, que de hecho surgieron como estrategias contra el poder estatal.

\section{La intervención de la Iglesia Católica en las experiencias de educación complementaria en la zona norte del Gran Buenos Aires}

En este apartado avanzaremos en las particularidades que adquiere la intervención de la Iglesia Católica en la construcción de demandas educativas en la zona norte del conurbano, tomando como referencia las experiencias de educación complementaria que desde la década de los ochenta y los noventa tienen lugar en los barrios periféricos del Obispado de San Isidro. 
Los espacios de educación complementaria, comúnmente llamados centros de "apoyo escolar", a los que referimos aquí son iniciativas generalmente organizadas por la sociedad civil que se crean con el objetivo de brindar a los niños de sectores populares una propuesta pedagógica alternativa o complementaria a la educación formal, además de intervenir en el desarrollo integral del niño y su familia. ${ }^{21}$

Entre estos espacios, las experiencias que pertenecen a la diócesis muestran en la actualidad un trabajo sostenido en el tiempo y de progresiva sistematización que, según entendemos, se relaciona estrechamente con la obtención de subsidios y formación de recursos humanos que estos Centros logran en su vinculación con fundaciones privadas, ONGs, y el Estado, fundamentalmente a partir de su nucleamiento en la Red de Apoyos Diocesanos que funciona desde 1995 dentro de Cáritas en la diócesis de San Isidro. ${ }^{22}$

En función del objetivo que nos propusimos tomaremos como eje de análisis para este apartado el proceso de constitución de estas experiencias de educación complementaria y su progresivo nucleamiento en el trabajo en Red, vinculando este recorrido con las características específicas de este Obispado.

La diócesis de San Isidro comprende los partidos de San Fernando, San Isidro, Tigre, Vicente López y las secciones 1, 2 y 3 de las islas del Delta Bonaerense. Creado en 1957, este Obispado sobresale por su larga tradición en acciones dedicadas a la caridad. ${ }^{23} \mathrm{La}$ institución Cáritas diocesana, definida como "la caridad organizada" del Obispado, es el órgano que se dedica fundamentalmente a coordinar la obra social y caritativa de la diócesis y el trabajo solidario. ${ }^{24}$ Esta institución funciona a través de una Comisión interna y de los lazos que establece entre las Cáritas parroquiales y las redes que funcionan dentro del Obispado, entre ellas la de Apoyo Escolar. ${ }^{25}$ 
En sus orígenes los centros de apoyo escolar diocesanos surgen a partir de iniciativas - heterogéneas entre sí - a cargo de cuadros de base de la Iglesia Católica: voluntarios alineados en Cáritas parroquial, laicos nucleados en $\mathrm{CEB}$, grupos de jóvenes perteneciente a la "pastoral juvenil" o a partir de la gestión directa de algún clérigo, en general diáconos a cargo de capillas situadas en las villas y asentamientos.

El período en que se concentra su surgimiento, entre mediados de los ochenta y transcurso de los noventa, ubica a estas experiencias en una coyuntura específica de nuestro país caracterizada por los efectos acuciantes que deja la crisis hiperinflacionaria en 1989 así como las políticas de ajuste estructural, coyuntura a la que se suma el diagnóstico visto de riesgo de la población infantil frente a situaciones de abandono que, más allá del contexto de pobreza, pone el foco en las formas de organización familiar y también de la educación formal.

Si bien en su mayoría las experiencias de ayuda escolar involucran a voluntarios externos al barrio, las posibilidades de actuación de estos actores no se establece en el vacío sino en un marco de actuación que es previo y referido a formas locales de participación comunitaria. Para comprender los sentidos de este entramado de intervención - que complejiza formas tradicionales de filantropía propia de la historia de la Iglesia Católica en nuestro país, a la vez que perviven determinados elementos ligados a la caridad - debemos introducirnos en la historia y características que adquiere la penetración de la Iglesia en esta área del conurbano.

La entrada de la Iglesia Católica en los barrios periféricos de la zona norte del Gran Buenos Aires se produce principalmente hacia fines de los años 70. El punto de partida es el proceso de descentralización que llevan a cabo algunas congregaciones y parroquias cabeceras, muchas veces con el impulso que ejerce el Obispado. Se trata de un movimiento que se caracteriza a la vez por su articulación con procesos locales del 
territorio, tales como la solicitud de oficios religiosos por parte de vecinos políticamente influyentes, en general integrantes de comisiones de organización barrial en zona de loteos populares.

En la zona norte del conurbano esta articulación entre las parroquias cabeceras y la periferia se concreta bajo rasgos específicos. Uno que sobresale es la integración de estos referentes barriales en grupos de animación laica que adquieren un auge significativo en varias parroquias del Obispado de San Isidro hacia mediados de los años setenta y principios de los ochenta y que deriva, en momentos de dictadura militar, en la reorientación de la actuación política partidaria de muchos de ellos. ${ }^{26}$

El desplazamiento de la Iglesia hacia el territorio local se liga así con movimientos específicos dentro del catolicismo, que en menor o mayor medida legitima el Obispado, pero que son asumidos - e interpretados - por las congregaciones o los grupo de laicos que actúan en concreto en el lugar.

Como lo grafica nuestra indagación de campo en el barrio Bancalari en Tigre, el desplazamiento de la Iglesia en la zona norte a mediados de los ochenta incluyó la intervención activa en la toma no legal de terrenos - que con rasgos específicos tiene lugar aquí entre esa fecha y los noventa - en un marco de actuación pastoral más amplio encuadrado dentro de las iniciativas eclesiásticas provenientes de la "Proclama por un mundo mejor" impulsada por Pio XII en 1952 y que sobresalen por su trabajo de animación comunitaria. ${ }^{27}$

Con marcadas diferencias respecto de las experiencias de la zona sur, la conformación de las CEB en esta área del conurbano quedan sujetas, en parte a las orientaciones dadas por la teología de la liberación (sobre todo a partir de la intervención de algunos referentes eclesiales), más profundamente a las directrices que marcan programas de renovación pastoral que se implementa en la zona y que sobresalen por el discurso de tipo moderado y familiarista que ponderan. 
Según nuestros registros, las demandas en torno a la cuestión educativa que luego derivan en los ochenta y noventa en la creación de los espacios de apoyo escolar y jardín maternal incluyen, en su momento originario, el requerimiento por parte de los adultos responsables de los niños de un lugar para el cuidado de la infancia, sobre todo en vista de la creciente fragilidad de la protecciones sociales ligadas al trabajo formal, y el creciente deterioro de las condiciones de vida básicas.

Sin embargo el pasaje de este nivel de formulación de la demanda a la concreción de las obras específicas tiene lugar a partir de su articulación con las acciones pastorales que detallamos previamente, sobresaliendo en ese proceso la mutua compenetración entre los distintos actores sociales que se ponen en juego, a la vez que el peso diferencial de influencia que impone un marco signado por determinadas relaciones de poder.

En ese sentido, la organización de los centros de apoyo escolar diocesanos cuenta con la intervención fuertemente definitoria de los referentes eclesiales y de los voluntarios externos al barrio y se nutre con los aportes económicos provenientes de parroquias céntricas, así como fundaciones, colegios y barrios privados.

Esto no implica obscurecer el impulso que también le imprime el trabajo comunitario cada vez más sostenido proveniente de la actuación de quienes habitan los barrios periféricos. En momentos de la crisis hiperinflacionaria, tuvieron lugar un conjunto de prácticas de acción colectiva, tal la constitución de las ollas populares, emprendimientos comunitarios, conforman rutinas y experiencias nuevas para los pobladores que se asientan, así como relaciones inéditas, en este caso mediadas por la Iglesia que redundan en el sostenimiento de la obras que comienzan a levantarse. ${ }^{28}$

En un escenario marcado por la creciente subsidariedad del Estado, la implementación misma de los programas sociales de orientación 
focalizada incluye, aún con los límites que impone una política de características compensatorias, un campo de participación y discusión entre los vecinos que, aún desde sus márgenes, recaen sobre las obras destinadas a la infancia. En ese sentido, la obtención del plan PAIS (en buena medida ligada con la gestión llevada a cabo por representantes de la Iglesia) comprende la concurrencia regular de los vecinos a reuniones en las cuales las discusiones acerca de la organización de la distribución del subsidio se extienden hacia otras cuestiones generales, tales como el problema de los niños y sus cuidados. ${ }^{29}$

La progresiva sistematización de los centros de apoyo escolar durante la década de los noventa expone el campo de límites y posibilidades para la intervención popular en la construcción de demandas educativas. Un aspecto a resaltar es la relevancia que adquiere entre estas iniciativas el trabajo en Red - en detrimento de la articulación de cada uno de los centros con organizaciones de base de la misma zona de influencia - y la vinculación con asociaciones de la sociedad civil ligadas a fundaciones privadas y de orientación filantrópica.

Un punto de inflexión para las iniciativas de educación complementaria de la zona norte lo marca la creación de la Red de Apoyos Escolares Diocesanos en 1995. Si bien el origen de esta red se liga con la creciente ruptura entre los centros diocesanos con una red no confesional de existencia previa, un aspecto a considerar es la intervención activa del Obispado quien venía impulsando desde inicios de los noventa, a través de la Comisión diocesana de Cáritas, la articulación de las experiencias parroquiales, sobre todo de aquellas referidas al trabajo con la infancia, la educación y el trabajo.

Podemos decir que la constitución de la red diocesana ha modificado significativamente la relación entre las iniciativas individuales de apoyo escolar y Cáritas, y con ello las condiciones de trabajo al interior de cada centro. Básicamente, el nucleamiento en red favoreció el intercambio 
de información entre los centros, el acceso a capacitación diversa y sistemática, y la gestión cada vez más efectiva para la solicitud de recursos y subsidios ante el Estado, fundaciones privadas y particulares. ${ }^{30}$

Junto con la obtención de recursos, la integración de las experiencias de educación complementaria en la Red Diocesana fortalece el control del Obispado en aspectos significativos del desenvolvimiento de estas experiencias. Entre otros, la intervención del Obispado comprende en la actualidad su creciente injerencia en discusiones claves que cruzan a las experiencias (respecto a la orientación del trabajo, el lugar de la evangelización, la articulación con el sistema formal de enseñanza) y también en la resolución de conflictos diversos, sobre todo referidos a las condiciones de trabajo voluntario. En líneas generales podemos decir que en la coyuntura actual, advertimos una creciente presencia ahora de las instancias jerárquicas de la Iglesia en las experiencias de educación complementaria, redundando en menor o mayor medida en el carácter "eclesial" de los espacios, que en su origen han estado en buena medida ligadas a iniciativas provenientes del campo de actuación popular. ${ }^{31}$ Este proceso de progresiva intervención del Obispado en el problema de la educación complementaria sobresale por la creciente interlocución que adquieren estas experiencias con el Estado y las instancias oficiales tal el Ministerio de Educación de la Nación.

\section{Algunas conclusiones}

Según se describe en ambos casos de estudio se hace evidente un proceso de creciente interés de la Iglesia Católica en la cuestión social y asociado a ello una progresiva intervención en el territorio. Entendemos que esta intervención se tramita en términos territoriales y comunitarios, en sintonía con la orientación hegemónica dentro del campo del 
Tercer Sector que se apoya en el discurso moral de la sociedad civil, en el sentido de oponerla a las prácticas corruptas, ineficientes y/o coercitiva del Estado. Estas modalidades de intervención se concretizan bajo formas específicas e históricas en las zonas que integran los Obispados de Quilmes y San Isidro.

Teniendo en cuenta el nivel de la construcción de demandas, las luchas por tierra y vivienda en las experiencias de tomas y asentamientos en Quilmes se apoyan en una trama organizativa previa, que recupera tradiciones sindicales y partidarias de sus dirigentes, a la cual se suman los militantes de base, prioritariamente desde las CEB, ocasionando conflictos con la cúpula diocesana debido a su orientación crítica.

En cambio, la problematización de la cuestión educativa en la zona norte incluye la actuación activa de la Iglesia en el proceso mismo de construcción de demandas, integrando las formulaciones que provienen de los sectores populares (caracterizadas por su fragmentación y vinculación relativa con cursos de acción política partidaria y sindical) a las propuestas que orientan los cuadros de base de la Iglesia.

Por otro lado, si bien en ambos casos se registra la presencia de las CEB en estas iniciativas populares, debemos advertir que bajo esta denominación se concretizan modalidades diversas, que según entendemos se ligan a las tradiciones diocesanas de intervención pastoral, a su relación con el clero regular o secular y a las trayectorias de los sujetos que las integran. Vemos como en el caso de la zona norte, las CEB quedaron significativamente mediatizadas por movimientos laicos que se entroncan en la posturas moderadas pre-conciliares, mientras en la zona sur fueron protagónicas en los movimientos urbanos de tomas de tierras, inscribiéndose mayoritariamente en el catolicismo liberacionista.

Hay que considerar al respecto que la participación en ámbitos eclesiales, y especialmente en las CEB, permitió a los sectores populares durante las dictaduras de los años '70 en toda Latinoamérica, canalizar 
acciones de resistencia, protesta y/o de expresión cultural, ante la clausura y represión operadas contra las organizaciones sociales y políticas, y al mismo tiempo como expresión de ruptura de lazos tradicionales de representación. (Villareal, 1985; Levine y Mainwaring, 2001). Pero creemos necesario discutir cierta visión restringida del apoyo de la Iglesia a iniciativas populares que identificamos en nuestro medio, en la medida en que invisibiliza un campo de lucha ideológica que se desarrolla en la frontera entre lo político y lo religioso.

En ese sentido no es casual que en ambos casos estas demandas populares sean referenciadas en el marco de esta institución jerárquica y controvertida, teniendo en cuenta no obstante que frente a un contexto de crisis de representación y de capacidad de mediación de partidos y sindicatos, la Iglesia se torna un espacio de refugio mas flexible y/o eficiente que la maquinaria clientelar estatal.

Esta "ventaja comparativa" del aparato eclesial se traduce nuevamente en la especificidad de los casos analizados. En el obispado de San Isidro la integración de las organizaciones de base ligadas a la cuestión educativa les habilita una capacidad diferencial para la obtención de recursos por las características socioeconómicas del entorno de la diócesis (que se traduce en la entrada significativa de donaciones y subsidios). Mientras que en el caso de Quilmes la ventaja comparativa obtenida por las organizaciones de tierra y vivienda que buscan apoyo de la institución, consiste en poner de su parte la mediación del Obispado ante el estado, como estrategia para resistir la clientelización sobre estas demandas.

La lógica subyacente en ambos casos a este movimiento de orientación a la cuestión social es en definitiva la búsqueda de legitimidad para reposicionar a la institución en el escenario nacional, a partir de atribuirse la representación de los intereses de los sectores pauperizados. En este movimiento coincide con ciertos procesos desencadenados en el Estado y contribuye entonces en: (a) los procesos de terciarización/deses- 
tatalización de las funciones sociales del Estado; y (b) la generación de "efectos de Estado", en el sentido de la despolitización del campo de la sociedad civil.

Respecto del proceso de terciarización, aunque no lo hemos desarrollado aquí, nuestros casos de estudio dan cuenta de cómo las agencias eclesiales gestionan la implementación de planes sociales del Estado y programas educativos.

Con relación al "efecto de despolitización", observamos que el mismo se operativiza a través de la habilitación desde las agencias eclesiales de espacios públicos no estatales y no políticos. Estos espacios se presentan como democráticos en un doble sentido: porque no imponen una condición confesional a las demandas y organizaciones que amparan, por lo cual pueden contribuir a recrear prácticas e identidades de oposición/ resistencia frente al Estado. Y en segundo lugar porque aparentemente no requieren una contraprestación, es decir, no establecen una mecánica de "chantaje clientelar" inmediatista, como ocurre en el clientelismo partidario o estatal (lo cual no quiere decir que no exista o no se espere esta contraprestación).

A la vez estos espacios se presentan como no-políticos, lo cual es leído positivamente como no corrupto, pero sobre todo como no-parcializado, lo cual responde a la nueva orientación conciliadora de la Iglesia que rechaza el compromiso de los agentes pastorales con sujetos "politizados", como parte del trabajo religioso legítimo. Sin embargo está claro que la institución históricamente ha disputado su lugar en el campo político.

El efecto de despolitización radica entonces en que los sujetos, para ocupar estos espacios "no políticos", deben ceder la representación de sus intereses a la institución. En el caso de Quilmes, vimos que el Obispado media entre las organizaciones y el Estado en relación a la demanda de tierra y vivienda (de hecho asume su representación), y en San 
Isidro gestiona demandas educativas que se sustraen de su orientación al Estado. Ello condiciona a estas demandas y organizaciones en el sentido de que son orientadas a configurarse siempre de manera sectorial y localizada, obturando su referencia a la constitución de un orden social global y de allí su posibilidad de configuración como sujetos políticos.

Para finalizar, queremos señalar que si bien nuestro objetivo en esta ponencia ha sido profundizar sobre los condicionamientos de estas intervenciones de la Iglesia de vocación hegemónica sobre la configuración de demandas y organizaciones del campo popular (cuestión muchas veces abordada desde estudios especializados de forma sesgada a partir de su identificación con las categorías locales), no desconocemos la capacidad constitutiva de los sujetos de re-apropiarse en cierta medida de estos espacios en función de sus intereses.

\section{Notas}

1 Licenciadas en Ciencias Antropológicas. Correos electrónicos: marcelawoods@tutopia.com, laurasantillan@hotmail.com.

2 Nos referimos al Proyecto de Investigación sobre: "Escuelas, modos de organización familiar y políticas estatales en el marco de procesos de desigualdad social y diversidad sociocultural en América Latina. Una mirada histórico-etnográfica”, dirigido por María Rosa Neufeld y financiado por la Universidad de Buenos Aires.

3 Las "políticas focalizadas" responden a este carácter asistencialista puesto que se destinan a socorrer a grupos en crisis de reproducción social, que no pueden resolver sus necesidades en el mercado, una vez perdido el marco de derechos sociales obligatorios. En este marco es que Grassi utiliza también el concepto de "terciarización", extrapolándolo del ámbito de la producción (es decir la compra a terceros de servicios o partes necesarias pero que no hacen al núcleo de la producción de una firma o son de demanda estacional), para referirse a intervenciones sociales llevadas a cabo por ONGs y otras agencias, que son transitorias y no vinculantes. 
4 Siguiendo a Poulantzas, Trouillot señala en primer término el "efecto de aislamiento", refiriéndose a la producción de un tipo particular de sujeto, los ciudadanos individualizados, atomizados, que serían aparentemente iguales en una supuesta esfera pública indiferenciada, como rasgo clave de la política estatal. A partir de allí identifica y caracteriza otros efectos de estado: de "identificación", de "legibilidad" y de "espacialización".

5 Entendemos por territorialización una transformación operada tanto en los dispositivos de intervención social como en las formas de organización y lucha de los sectores populares, ligada a crecimiento del desempleo y la pobreza desde los años'70. Indica el desplazamiento al espacio barrial (espacio del consumo y la reproducción de una parte de la fuerza de trabajo) de conflictos y nuevas formas de lucha de clases, no centradas en la producción, y el desarrollo de mecanismos de procesamiento de estos conflictos en el terreno, tales como la descentralización estatal, el clientelismo y la nueva filantropía.

6 Grassi señala que el lanzamiento del Plan Social de 1993 marca un momento de consolidación de la "desestatalización", vía la delegación de la función social a organizaciones de la sociedad civil con fuerte legitimidad social, entre las que se destaca Cáritas.

7 El Tercer Sector o Sector Social toma su denominación para diferenciarse del Estado y el mercado, inscribiéndose en una tradición ideológica en la que sociedad civil y mercado son espacios a-políticos. Integran este campo las organizaciones definidas como "no estatales y sin fines de lucro". Reconociendo una diversidad de trayectorias y objetivos de estas entidades en la Argentina, debe señalarse que este espacio se consolida como campo y toma protagonismo central en los ' 90 de la mano de las ya mencionadas reformas en el Estado y de las recomendaciones de los organismos internaciones de crédito y sus nuevas líneas de financiamiento (Karaman, Trinchero y Woods, 2001).

8 Esta noción moderna de sociedad civil que surge en el siglo XVIII marcando una esfera diferenciada que abarca las interacciones sociales y el mercado, y que postula al Estado como una entidad universal y abstracta, es luego deconstruída por Marx, quien señala que el Estado expresa las particularidades (contradicciones) de la sociedad civil y es instrumento de la dominación de clase (Manzano et al., 2004)

9 El análisis que sigue se basa en los registros de tipo etnográfico construidos en el marco de nuestros trabajos de campo - independientemente entre sí - en la zona 
sur y norte del Gran Buenos Aires. Se trata de una indagación que incluye observación participante y entrevistas realizadas a: (1) zona sur: referentes de organizaciones de base, agentes pastorales de distinta jerarquía y funcionarios municipales. (2) en la zona norte: responsables (docentes y directivos) de espacios escolares, referentes de organizaciones de base, voluntarios de cáritas, pobladores.

10 Según el Instituto Nacional de Estadísticas y Censos (INDEC) se considera hogares con Necesidades Básicas Insatisfechas (NBI) a aquellos que presentan alguna de las siguientes condiciones: hacinamiento (más de tres personas por cuarto), hábitat en viviendas de tipo inadecuado, sin condiciones sanitarias (sin retrete), que tiene algún niño en edad escolar (de 6 a 12 años) que no asiste a la escuela, que tiene cuatro o más personas por miembro ocupado y que el jefe del hogar no tiene cumplida la escolaridad básica.

11 Nos referimos a las nuevas formas de hábitat que surgen en el sur del Gran Buenos Aires a inicios de la década de los 80 a partir de la ocupación "ilegal" - y no ilegítima - de tierras públicas y privadas, a través de acciones planificadas o espontáneas por parte de pobladores "pobres" o en proceso de empobrecimiento, que producen también nuevas conflictividades y tramas organizativas en torno a demandas específicas (Cravino, 1999).

12 La ordenanza 8289/98 creó al mismo tiempo un Fondo Municipal de Tierra y Vivienda, que supone un presupuesto anual propio (que debe ser aprobado por decreto cada año), que proviene principalmente del $40 \%$ de los derechos de construcción que recauda la comuna y del $40 \%$ de lo producido por la venta de terrenos e inmuebles municipales.

13 Entre tanto es designado en mayo de 1997, Gerardo Farrell como Obispo Coadjutor, quien fallece en junio del 2000.

14 Uno de los catalizadores principales de este conflicto fue el Concilio Vaticano II, convocado por el papa Juan XXIII entre los años 1962 y 1965 (cuyo objetivo central era el aggiornamiento de la Iglesia), y sus repercusiones en Latinoamérica.

15 Debe ser tenido en cuenta que las posturas críticas fueron dándose progresivamente en las prácticas y discursos del Obispo Novak, para lo cual tuvo un gran peso su participación como co-presidente en el Movimiento Ecuménico por los Derechos Humanos (MEDH).

16 Pensando en términos de la teoría de los Campos Sociales de P. Bourdieu, lo que se pierde de vista al suponer acciones altruistas (a veces a partir de la teoría de la 
Acción Racional) motivadas por agentes religiosos, es el beneficio (no económico sino simbólico) que otorga el interés por el desinterés, tanto dentro del campo religioso como del político, en función de asegurar la propia posición social y reproducción dentro del campo en cuestión (sin que ello suponga necesariamente estrategias concientes y racionales por parte de los agentes).

17 Novak destinó como Vicario de Pastoral Social a uno de los curas hasta ese momento mas comprometidos en la atención de las familias de los desaparecidos, el P. Miguel Hrymacz. Sin embargo, al momento de renovar las designaciones en 1986, decidió no dar continuidad a esta Vicaría, tal vez porque con el advenimiento de la democracia, los conflictos territoriales retrocedieron por pocos años frente a la politización de ciertas demandas y resurgimiento de conflictos a nivel nacional en torno al trabajo, liderados por los gremios.

18 Uno de estos dirigentes provenía de una larga trayectoria de militancia política partidaria en una organización de identidad peronista pero independiente del Partido Justicialista.

19 Actualmente los fondos de la cuenta especial de este Consejo ascienden, según estiman las organizaciones que lo integran, a cerca de 1.000 .000 de pesos. Se nuclean hoy en el Consejo alrededor de 60 organizaciones de base de tierra y vivienda (organizaciones de villas y asentamientos, el Consejo de Asentamientos, sociedades de fomento, cooperativas de vivienda etc.).

20 El nuevo Obispo Stökler reestructuró los ámbitos diocesanos interesados en lo social, poniendo bajo la órbita de la Vicaría de Pastoral Social (que pasó a llamarse de la Solidaridad) y manteniendo al mismo Vicario, a Cáritas diocesana y a la Fundación Novak, confirmando y ampliando así la importancia de la cuestión social para el Obispado.

21 El trabajo en estos centros, llevado a cabo a contra turno de la escuela común, comprende la implementación de actividades de ayuda escolar, como así también acciones específicas de enseñanza de matemática y lengua, además de la ejecución de diversos talleres a cargo de maestros comunitarios y/o docentes con título habilitante.

22 La Red de Apoyos Escolares Diocesanos se propone como objetivo ser responsable de la obtención de recursos y de la generación de vínculos estrechos entre las experiencias ligadas a la atención de niños en edad escolar. Esta red la conforman alrededor de 40 centros distribuidos en los barrios de Las Flores de Vicente López, La cava de San Isidro, Baires Bancalari de Tigre, San Jorge de San Fernando, entre otros. 
23 Actualmente el Obispo desde 1985 de San Isidro Mons. Jorge Casaretto preside Cáritas a nivel nacional, institución que tiene como objetivo la animación y coordinación de la pastoral caritativa de la Iglesia a nivel del país desde 1956.

24 En la diócesis de San Isidro, siguiendo la tendencia general que distingue nuestro país de otros, Cáritas diocesana funciona como área diferenciada de la Pastoral Social.

25 Dentro del Obispado de San Isidro funcionan la red de Jardines de Infantes, la red de Comedores, la red de Apoyos escolares, y la red de Capacitación laboral.

26 Entre estos movimientos de animación laica de la Iglesia Católica en nuestro país sobresalen por su adhesión los "Cursillos de la Cristiandad" que se gestaron en la década del 40 en España con el objetivo de establecer una impronta significativa del laicado dentro de la Iglesia. Entre sus distintas modalidades, el cursillo "De colores", de gran arraigo en la diócesis de San Isidro en los años 70 y 80 tiene como objetivo buscar la interpelación a través de formas "vivenciales de la experiencia" de valores ligados al orden social y la familia.

27 En el barrio Bancalari la parroquia cabecera implementa en el año 1982 el programa Nueva Imagen de Parroquia que se inscribe dentro del Movimiento Un Mundo Mejor y que implica la organización comunitaria de la evangelización en etapas pautadas de inserción barrial a través de la conformación de Comunidades Eclesiales de Base y la concreción de distintos niveles de trabajo pastoral (familiar, sectorial, parroquial).

28 Resulta relevante advertir que el desplazamiento de voluntarios de Cáritas y clérigos en los barrios periféricos de la zona norte también redunda en la progresiva articulación entre las actividades de la Iglesia y las acciones de los pobladores que se asientan a través de la toma no legal de terrenos, sobre todo en la formulación y organización de las demandas (respecto al problema de la luz eléctrica, la regularización dominial, la obtención de agua, entre otros) y sus reclamos frente a empresas privadas y agencias del Estado.

29 El Programa Alimentario Integral y Solidario (PAIS) fue implementado por el Ministerio de Acción Social de la provincia de Buenos Aires hacia fines de 1989 y 1991 en una coyuntura de hiperinflación, y se planteó como objetivos articular la distribución de subsidios para la cobertura alimentaria de comedores comunitarios con la incorporación de la población en proyectos de generación de empleos y de organizaciones sociales a redes preexistentes comunitarias (Chiara, 1996). 
30 Cáritas San Isidro cuenta con un programa específico de recaudación de fondos "Ayudarte" que en la actualidad se propone la cobertura de becas que alcanza alrededor de 6.500 niños que concurren a los centros de la diocésis. Este programa, creado dentro del Obispado en 1993, cuenta con un equipo técnico para la administración de los recursos que se derivan a los centros y que provienen de la donación que realizan empresas y particulares a través de sus tarjetas de crédito.

31 Este proceso de progresiva intervención del Obispado en el problema de la educación complementaria sobresale por la creciente interlocución que adquieren estas experiencias con el Estado y las instancias oficiales tal el Ministerio de Educación de la Nación.

\section{Bibliografía}

BOURDIEU, Pierre

$2000 \quad$ Intelectuales, política y poder, Buenos Aires, Eudeba.

CHIARA, Magdalena

1996 "El modelo de gestión del programa alimentario integral y solidario: una relectura para su implementación", in PENAALVA \& ROFMAN, Desempleo estructural, pobreza y precariedad", Nueva Visión.

CRAVINO, Cristina

1998 "Los asentamientos del Gran Buenos Aires. Reivindicaciones y contradicciones", en VVAA, Antropología social y política. Hegemonía y poder: el mundo en movimient, Buenos Aires, Eudeba.

DI STEFANO, Roberto \& ZANATTA, Loris

$2000 \quad$ Historia de la Iglesia Argentina. Desde la Conquista hasta fines del siglo XX, Buenos Aires, Grijalbo/Mondadori.

FORNI, Floreal, H. \& CÁRDENAS, Luís A.

2002 "Formas de acción colectiva en un proceso de desarrollo local espontáneo. El surgimiento de barrios en Cuartel V, Partido de Moreno", in FORNI, Floreal H. (ed.), De la exclusión a la organización. Hacia la integración de los pobres en los nuevos barrios del conurbano bonaerense, Buenos Aires, Ediciones Ciccus. 
FORNI, Floreal H. \& GÓMEZ, Graciela 2002 "Entre cruces y galpones. La religión de los pobres en los barrios del conurbano", in FORNI, Floreal H. (ed.), De la exclusión a la organización. Hacia la integración de los pobres en los nuevos barrios del conurbano bonaerense, Buenos Aires, Ediciones Ciccus.

IZAGUIRRE, Inés \& ARISTIZÁBAL, Zulema

1988 Las tomas de tierras en la zona Sur del Gran Buenos Aires. Un ejercicio de poder en el campo popular, Buenos Aires, CEAL.

GRASSI, Estela

"La política social del neoliberalismo. Supuestos que orientan la acción política y problemas pendientes", Buenos Aires, mimeo.

2003 Politicas y problemas sociales en la sociedad neoliberal: la otra década infame (I), Buenos Aires, Espacio.

GRASSI, Estela; HINTZE, Susana \& NEUFELD, María Rosa

1996 "Crisis del Estado de Bienestar y construcción del sentido de las políticas sociales", Cuadernos de Antropología Social, 9, Buenos Aires.

HOLLOWAY, John

1994 Marxismo, estado y capital, Buenos Aires, Cuadernos Del Sur.

LEVINE, Daniel H. \& MAINWARING, Scott

2001 "Religión y protesta popular en América Latina: experiencias contrastantes", in ECKSTEIN, Susan (ed.), Poder y protesta popular. Movimientos sociales latinoamericanos, México, Siglo XXI.

MANZANO, Virginia

2003 "Tradiciones asociativas, políticas estatales y modalidades de acción colectiva: análisis de una organización piquetera”, en prensa en revista Intersecciones en Antropología, Olavarría.

MANZANO, Virginia; NOVARO, Gabriela; SANTILLÁN, Laura \& WOODS, Marcela 2004 "Introducción a la problemática de la desigualdad. Hacia un abordaje antropológico", in NEUFELD, M. R., Antropología social y politica. Desigualdad y acción colectiva, OPFyL, UBA. 
MERKLEN, Denis

1991 Los asentamientos en La Matanza. La terquedad de lo nuestro, Buenos Aires, Catálogo.

MEIKSINS WOOD, Ellen

2000 Democracia contra capitalismo, Buenos Aires.

OSZLAK, Oscar

1986 "Los sectores populares y el derecho al espacio urbano", Punto de vista, 16, Buenos Aires.

PÍREZ, Pedro

1994 Buenos Aires metropolitana. Política y gestión de la ciudad, Buenos Aires, CEAL - CENTRO.

RIVAROLA, María de los Milagros

1986 "Comunidades de Base: un compromiso de los laicos para volver a la Iglesiacomunidad”, Sociedad y Religión, 3, Buenos Aires.

RODRÍGUEZ KARAMAN, Gustavo; TRINCHERO, H. Hugo \& WOODS, Marcela

2001 "La Consulta del Banco Mundial a la sociedad civil en la Argentina. Economía política de la participación", Realidad Económica, IADE, 180: 91-111, Buenos Aires.

SOUSA SANTOS, Boaventura de

1998 De la mano de Alicia. Lo social y lo político en la postmodernidad, Bogotá, Ed. Uniandes/Universidad de os Andes/Siglo del Hombre Ed.

TROUILLOT, Michel-Rolph

2001 "La antropología del Estado en la era de la globalización. Encuentros cercanos de tipo engañoso", Current Anthropology, 42(1).

VILLAREAL, Juan

1985 "Los hilos sociales del poder", in JOZAMI, Eduardo et al., Crisis de la dictadura argentina. Politica económica y cambio social 1976-1983, Buenos Aires, Siglo XXI. 
ZIBECHI, Raúl

Genealogía de la revuelta. Argentina: la sociedad en movimiento, La Plata, Letra libre/Nordan-Comunidda.

\begin{abstract}
The aim of this paper is to analyse the types of intervention of Catholic Church agencies in the building of territorially grounded sectorial demands made by popular stratum from Buenos Aires outskirts, relating these demands to the transformation of social public policies into assistencialismo [clientelistic policy] and outsourcing in the past decades. To accomplish it, we will present and compare two case studies from an ethnographic standpoint: the building of educational demands and its progressive integration into structures binded to the bishopric of San Isidro; and the intervention of the Vicariate of Quilmes bishopric's Social Pastoral in the social conflicts involving organizations for land and home and the local government. Thus, our purpose is to show the limits and possibilities of these types of intervention by the Catholic Church in the recomposition of popular organizational forms and to stress local and historical specificities of each diocese, as well as their common logic, which guide them.
\end{abstract}

KEY-WORDS: Church, State, social question, education, land and home.

Aceito em agosto de 2005. 